\title{
(2) OPEN ACCESS \\ Social and ethnic group differences in healthcare use by children aged $0-14$ years: a population-based cohort study in England from 2007 to 2017
}

\author{
Charles Hamish Coughlan 주, Judith Ruzangi, Francesca K Neale,

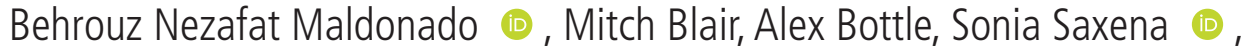 \\ Dougal Hargreaves
}

\begin{abstract}
- Additional supplemental material is published online only. To view, please visit the journal online (http://dx.doi. org/10.1136/archdischild2020-321045)
\end{abstract}

Department of Primary Care and Public Health, Imperial College London School of Public Health, London, UK

\section{Correspondence to}

Dr Charles Hamish Coughlan, Department of Primary Care and Public Health, Imperial College London School of Public Health, London W6 8RP, UK: chcoughlan@doctors.org.uk

Received 9 November 2020 Accepted 20 May 2021
Check for updates

(c) Author(s) (or their employer(s)) 2021. Re-use permitted under CC BY-NC. No commercial re-use. See rights and permissions. Published by BMJ.

To cite: Coughlan $\mathrm{CH}$ Ruzangi J, Neale FK, et al. Arch Dis Child Epub ahead of print: [please include Day Month Year]. doi:10.1136/ archdischild-2020-321045

\begin{abstract}
Objective To describe social and ethnic group differences in children's use of healthcare services in England, from 2007 to 2017.

Design Population-based retrospective cohort study. Setting/Patients We performed individual-level linkage of electronic health records from general practices and hospitals in England by creating an open cohort linking data from the Clinical Practice Research Datalink and Hospital Episode Statistics. 1484455 children aged $0-14$ years were assigned to five composite ethnic groups and five ordered groups based on postcode mapped to index of multiple deprivation.

Main outcome measures Age-standardised annual general practitioner (GP) consultation, outpatient attendance, emergency department (ED) visit and emergency and elective hospital admission rates per 1000 child-years.
\end{abstract}

Results In 2016/2017, children from the most deprived group had fewer GP consultations (1765 vs 1854 per 1000 child-years) and outpatient attendances than children in the least deprived group (705 vs 741 per 1000 child-years). At the end of the study period, children from the most deprived group had more ED visits (447 vs 314 per 1000 child-years) and emergency admissions (100 vs 76 per 1000 child-years) than children from the least deprived group.

In 2016/2017, children from black and Asian ethnic groups had more GP consultations than children from white ethnic groups (1961 and 2397 vs 1824 per 1000 child-years, respectively). However, outpatient attendances were lower in children from black ethnic groups than in children from white ethnic groups (732 vs 809 per 1000 child-years). By 2016/2017, there were no differences in outpatient, ED and in-patient activity between children from white and Asian ethnic groups. Conclusions Between 2007 and 2017, children living in more deprived areas of England made greater use of emergency services and received less scheduled care than children from affluent neighbourhoods. Children from Asian and black ethnic groups continued to consult GPs more frequently than children from white ethnic groups, though black children had significantly lower outpatient attendance rates than white children across the study period. Our findings suggest substantial levels of unmet need among children living in socioeconomically disadvantaged areas. Further work is needed to determine if healthcare utilisation among children from Asian and black ethnic groups is proportionate to need.

\section{What is already known on this topic?}

- Between 2007 and 2017, overall rates of general practitioner (GP) consultation fell across England, while unscheduled care use and outpatient attendances increased substantially.

- These results may mask differences in healthcare use between children from different socioeconomic and ethnic backgrounds.

- There is some evidence of variation in child health outcomes, with worsening infant mortality seen in more deprived areas and certain ethnic groups.

\section{What this study adds?}

- This study demonstrates divergent patterns of healthcare use along a social gradient among children living in England.

- While the use of GP and unscheduled care services remains relatively high in Asian children, children from black ethnic groups are less likely to access specialist outpatient care despite rising health needs.

- These results suggest substantial levels of unmet need among children living in more deprived areas.

\section{INTRODUCTION}

Child health inequalities are widening in the UK. ${ }^{12}$ Social gradients exist across various child health conditions, including dental caries, ${ }^{3}$ asthma attacks ${ }^{4}$ and mental illness. ${ }^{5}$ In England, rates of childhood obesity and infant mortality are higher in children from black African Caribbean groups than among their peers. ${ }^{2}$ Universal health coverage can mitigate health inequalities and improve population health by reducing the mismatch between clinical need and healthcare use. ${ }^{6}$ The UK National Health Service (NHS) provides healthcare free at the point of delivery, and international comparisons suggest it has historically been one of the world's most equitable health systems. ${ }^{7}$ A large cross-sectional study conducted in 2002 suggested that self-reported health status, rather than parental socioeconomic status or ethnicity, was the best predictor of healthcare use among British children and young people (CYP). ${ }^{8}$ However, there remains a professional, 
legal and moral duty to ensure equity of access to services for CYP across income and ethnic groups, particularly in view of recent evidence on rising child poverty levels, ${ }^{9}$ and a disproportionate increase in the incidence of adverse child health outcomes among CYP from disadvantaged backgrounds. ${ }^{10} 11$ These associations may be mediated by reduced access to or use of health services, emphasising the need to reassess social and ethnic group differences in healthcare use.

When analysing patterns of healthcare use, it is important to consider activity in all settings (online supplemental figure 1). The cradle-to-grave NHS model is centred on general practitioners (GPs), family physicians who provide first contact care to acutely unwell patients, support chronic disease management and act as gatekeepers for onward referral to specialist services. ${ }^{12}$ GPs also provide preventive care including childhood vaccinations and development checks. We have previously described changes in children's healthcare use in England between 2007 and $2017 .{ }^{13}$ We reported increasing emergency department (ED) and outpatient activity, and decreasing GP consultation rates and in-patient activity among children aged 0-14 years. However, these overall trends may mask differences between CYP from different social and ethnic groups.

In this population-based, retrospective cohort study, we sought to describe differences in healthcare use among children aged 0-14 years and living in England, by healthcare setting, level of deprivation and ethnic group. We hypothesised that children from disadvantaged groups would use less planned and preventive primary and hospital care, resulting in more chaotic disease control, higher rates of acute illness and greater use of emergency services. Our secondary objective was to determine whether between-group differences in healthcare use within our study cohort changed between 2007 and 2017.

\section{METHODS}

\section{Study design, data sources and population}

We conducted a population-based retrospective cohort study using prospectively collected, longitudinal, patient-level data from the Clinical Practice Research Datalink (CPRD). This includes deidentified data on patient demographics, primary care consultations and secondary care referrals. CPRD is the largest validated primary care research database in the UK, representative for age, sex and ethnicity and encompassing $8 \%$ of the UK population. ${ }^{14}$

We linked CPRD to Hospital Episode Statistics (HES), which contains information on NHS hospital activity in England.

Our open cohort included all CYP aged 0-14 years in HES-linked CPRD registered 'up to standard' general practices in England between 1 April 2007 and 31 July 2017. Each child contributed to the time of observation from birth or the date at which they registered at a participating general practice. Children remained in the cohort until they transferred out of practice, reached the age of 15 years, died or reached the end of the study period.

We assigned children to five composite, non-homogenous groups based on ethnic ancestry coding within the CPRD dataset (box 1).

These categories are recommended for use by the UK Office for National Statistics (ONS). ${ }^{15}$ Completeness of ethnicity coding within our dataset increased from $74.5 \%$ in $2007 / 8 \%$ to $87.8 \%$ in $2016 / 2017$. Each participant's postcode was used to allocate them to five ordered groups (most to least deprived) based on the Index of Multiple Deprivation. Index of Multiple Deprivation (IMD) is an official measure of relative deprivation which describes the proportion of children aged 0-15 years living in income-deprived neighbourhoods. ${ }^{16}$
Box 1 Ethnic group composition

White
English, Welsh, Scottish or Northern Irish.
Irish.
Gypsy or Irish traveller.
Any other White background.
Black
Black African.
Black Caribbean.
Any other Black background.
Asian
- Indian.
Pakistani.
Bangladeshi.
Chinese.
Any other Asian background.
Mixed
White and Black Caribbean.
White and Black African.
White and Asian.
Other mixed/multiple ethnic background.

\section{Outcomes}

Our main outcomes were GP consultations, outpatient attendances, $\mathrm{ED}$ visits and emergency and elective in-patient admissions. Practical details of how we used CPRD-HES linked data to derive these outcomes are described in online supplemental file $1 .{ }^{13}$ We defined a GP consultation as any face-to-face consultation for illness that took place on practice premises. We excluded routine preventive primary care visits, such as childhood immunisations and child development checks. We defined an outpatient attendance as a recorded consultation between a child and the intended specialist healthcare professional on the date of the appointment on the HES outpatient appointment dataset. We defined an ED visit as an attendance at a consultant-led ED capable of receiving acutely unwell patients, with a 24-hour services and full resuscitation facilities. We excluded visits to consultant-led single-specialty EDs such as walk-in rapid access eye casualty services. We defined an emergency admission as an unplanned admission to hospital based on acute clinical need and an elective admission as a hospital admission where the decision to admit could be separated in time from the admission itself.

\section{Analysis}

We calculated annual rates per 1000 child-years for each outcome by dividing the total number of events by the total child-years of observation, directly standardised by age (see online supplemental appendix 1 for more information). We calculated percentage change from baseline for each outcome in each social and ethnic group. We calculated ratios of activity at baseline and in $2016 / 2017$ by dividing the utilisation rate in the most deprived group by that in the least deprived group and dividing the rate for each ethnic group by that among children from white ethnic groups. We used Fieller's theorem to calculate the CIs for the ratios of two means. ${ }^{17}$ Due to changes in recording of ED data within the HES dataset, data are not comparable before and after 2010/2011. We used 2011/2012 as 
Table 1 Changes in rates of activity by social and ethnic group and healthcare setting

\begin{tabular}{|c|c|c|c|c|c|c|c|c|}
\hline $\begin{array}{l}\text { Outcome of } \\
\text { interest }\end{array}$ & IMD group & $\begin{array}{l}\text { Baseline } \\
\text { rate/1000 } \\
\text { child-years }\end{array}$ & $\begin{array}{l}2016 / 2017 \\
\text { rate/1000 child- } \\
\text { years }\end{array}$ & $\begin{array}{l}\text { Percentage change from } \\
\text { baseline }(95 \% \mathrm{Cl})\end{array}$ & $\begin{array}{l}\text { Ethnic } \\
\text { group }\end{array}$ & $\begin{array}{l}\text { Baseline } \\
\text { rate/1000 child- } \\
\text { years }\end{array}$ & $\begin{array}{l}2016 / 2017 \\
\text { rate/1000 Child- } \\
\text { years }\end{array}$ & $\begin{array}{l}\text { Percentage change from } \\
\text { baseline }(95 \% \mathrm{Cl})\end{array}$ \\
\hline \multirow[t]{5}{*}{ GP consultations } & $\begin{array}{l}1 \text { (least } \\
\text { deprived) }\end{array}$ & 2021 & 1854 & $-8.3(-4.1$ to -12.4$)$ & White & 2113 & 1824 & $-13.7(-11.1$ to -16.3$)$ \\
\hline & 2 & 1987 & 1817 & $-8.6(-4.2$ to -12.9$)$ & Black & 2404 & 1961 & $-18.4(-7.4$ to -29.4$)$ \\
\hline & 3 & 1999 & 1826 & $-8.7(-4.2$ to -13.1$)$ & Asian & 2989 & 2397 & $-19.8(-8.9$ to -30.7$)$ \\
\hline & 4 & 2001 & 1889 & $-5.6(-1.3$ to -9.9$)$ & Mixed & 2343 & 1951 & $-16.7(-3.6$ to -29.8$)$ \\
\hline & $\begin{array}{l}5 \text { (most } \\
\text { deprived) }\end{array}$ & 1978 & 1765 & $-10.8(-6.7$ to -14.8$)$ & Other & 1752 & 1663 & $-5.1(2.2$ to -12.3$)$ \\
\hline \multirow[t]{5}{*}{$\begin{array}{l}\text { Outpatient } \\
\text { attendances }\end{array}$} & $\begin{array}{l}1 \text { (least } \\
\text { deprived) }\end{array}$ & 486 & 741 & 52.5 (49.4 to 55.6$)$ & White & 641 & 809 & 26.2 (23.9 to 28.5 ) \\
\hline & 2 & 503 & 754 & 49.9 (46.5 to 53.3 ) & Black & 598 & 732 & 22.4 (12.7 to 32.1) \\
\hline & 3 & 499 & 735 & 47.3 (43.9 to 50.7 ) & Asian & 720 & 800 & 11.1 (2.7 to 19.6$)$ \\
\hline & 4 & 528 & 734 & 39.0 (35.6 to 42.4) & Mixed & 688 & 737 & $7.1(-3.6$ to 17.8$)$ \\
\hline & $\begin{array}{l}5 \text { (most } \\
\text { deprived) }\end{array}$ & 546 & 705 & 29.1 (25.8 to 32.4$)$ & Other & 325 & 465 & $43.1 \%$ (40.3 to 45.9$)$ \\
\hline \multirow[t]{5}{*}{ ED visits } & $\begin{array}{l}1 \text { (least } \\
\text { deprived) }\end{array}$ & 265 & 314 & 18.5 (16.2 to 20.7$)$ & White & 357 & 402 & $12.6(11.1$ to 14.1$)$ \\
\hline & 2 & 288 & 340 & 18.1 (15.5 to 20.6) & Black & 405 & 370 & $-8.6 \%(-2.0$ to -15.3$)$ \\
\hline & 3 & 313 & 373 & 19.2 (16.5 to 21.8$)$ & Asian & 378 & 390 & $3.2(-2.3$ to 8.7$)$ \\
\hline & 4 & 348 & 408 & 17.2 (14.5 to 19.9$)$ & Mixed & 383 & 374 & $-2.4(-9.8$ to 5.1$)$ \\
\hline & $\begin{array}{l}5 \text { (most } \\
\text { deprived) }\end{array}$ & 390 & 447 & 14.6 (11.9 to 17.4) & Other & 191 & 259 & 35.6 (31.7 to 39.5) \\
\hline \multirow[t]{5}{*}{$\begin{array}{l}\text { Emergency } \\
\text { admissions }\end{array}$} & $\begin{array}{l}1 \text { (least } \\
\text { deprived) }\end{array}$ & 67 & 76 & 13.4 (12.1 to 14.8$)$ & White & 97 & 95 & $-2.1(-1.1$ to -3.1$)$ \\
\hline & 2 & 70 & 79 & 12.9 (11.3 to 14.4$)$ & Black & 88 & 95 & 8.0 (3.6 to 12.3 ) \\
\hline & 3 & 70 & 89 & 27.1 (25.5 to 28.8) & Asian & 106 & 106 & $0.0(-3.85$ to 3.85$)$ \\
\hline & 4 & 81 & 96 & 18.5 (16.9 to 20.2$)$ & Mixed & 104 & 89 & $-14.4(-9.5$ to -19.4$)$ \\
\hline & $\begin{array}{l}5 \text { (most } \\
\text { deprived) }\end{array}$ & 93 & 100 & 7.5 (5.9 to 9.2 ) & Other & 39 & 64 & 64.1 (61.4 to 66.9$)$ \\
\hline \multirow[t]{5}{*}{ Elective admissions } & $\begin{array}{l}1 \text { (least } \\
\text { deprived) }\end{array}$ & 42 & 44 & 4.8 (3.6 to 5.9 ) & White & 65 & 55 & $-15.4(-14.55$ to -16.2$)$ \\
\hline & 2 & 44 & 54 & 22.7 (21.4 to 24.0$)$ & Black & 65 & 62 & $-4.6(-0.9$ to -8.3$)$ \\
\hline & 3 & 43 & 47 & 9.3 (8.0 to 10.6$)$ & Asian & 89 & 60 & $-32.6(-29.4$ to -35.7$)$ \\
\hline & 4 & 49 & 52 & 6.1 (4.8 to 7.4 ) & Mixed & 77 & 85 & 10.4 (6.3 to 14.5$)$ \\
\hline & $\begin{array}{l}5 \text { (most } \\
\text { deprived) }\end{array}$ & 57 & 57 & $0.0(-1.3$ to 1.3$)$ & Other & 29 & 36 & 24.1 (22.0 to 26.3) \\
\hline
\end{tabular}

Due to improvements in the completeness of ethnicity data during the study period, activity changes by ethnic group should be interpreted with caution.

Baseline year for GP consultations, outpatient attendances, emergency admission and elective admissions—2007/2008.

Baseline year for ED visits-2011/2012.

$\mathrm{ED}$, emergency department; $\mathrm{GP}$, general practitioner.

the baseline year for our analysis of trends in ED activity and $2007 / 2008$ as the baseline year for all other outcomes.

\section{PPI statement}

No patients or members of the public were involved in collecting or analysing data for this study, or in the writing or editing of this article.

\section{RESULTS}

Overall, 1484455 children from 408 GP practices contributed to this cohort study. From 1 April 2007 to 31 March 2017, there were 7604024 GP consultations, 981684 ED visits, 287719 emergency in-patient hospital admissions, 194034 elective in-patient hospital admissions and 2253533 outpatient visits among children aged $0-14$ years in our study population.

Table 1 presents changes in activity in each healthcare setting for children belonging to different social and ethnic groups. Absolute numbers are given for baseline year and 2016/2017 and percentage change from baseline shown for each group. Figure 1 presents trends in children's healthcare use between 2007 and 2017 by setting and social and ethnic group. Table 2 presents ratios of activity in different social and ethnic groups across the study period. Online supplemental tables 1 and 2 show the raw data used to create the graphs in figure 1 , for our analyses by IMD and ethnicity, respectively.

\section{Deprivation}

In 2016/2017, the most deprived CYP accounted for fewer GP consultations (1765 vs 1854 per 1000 child-years) and outpatient attendances (705 vs 741 per 1000) than the least deprived. In 2007/2008, the most deprived CYP had 2.1\% (95\% CI $1.7 \%$ to $2.6 \%$ ) fewer consultations than the least deprived. By $2016 / 2017$, this had widened to $4.8 \%$ (4.0\% to $5.6 \%)$. The social gradient for outpatient attendances reversed across the study period. The most deprived CYP had 12.4\% (10.9\% to $13.8 \%$ ) more attendances than the least deprived in $2007 / 2008$, but $4.9 \%(3.3,6.4 \%)$ fewer in 2016/17.

In contrast, the most deprived CYP had more ED visits (447 vs 314 per 1000), emergency admissions (100 vs 76 per 1000) and elective admissions (57 vs 44 per 1000) than the least deprived in 2016/2017. Ratios of activity in these settings were similar at baseline and in 2016/2017. 
Health Utilization Rates for Children under 15 years old by Index of Multiple Deprivation quintile and Healthcare Setting England 2007-2017
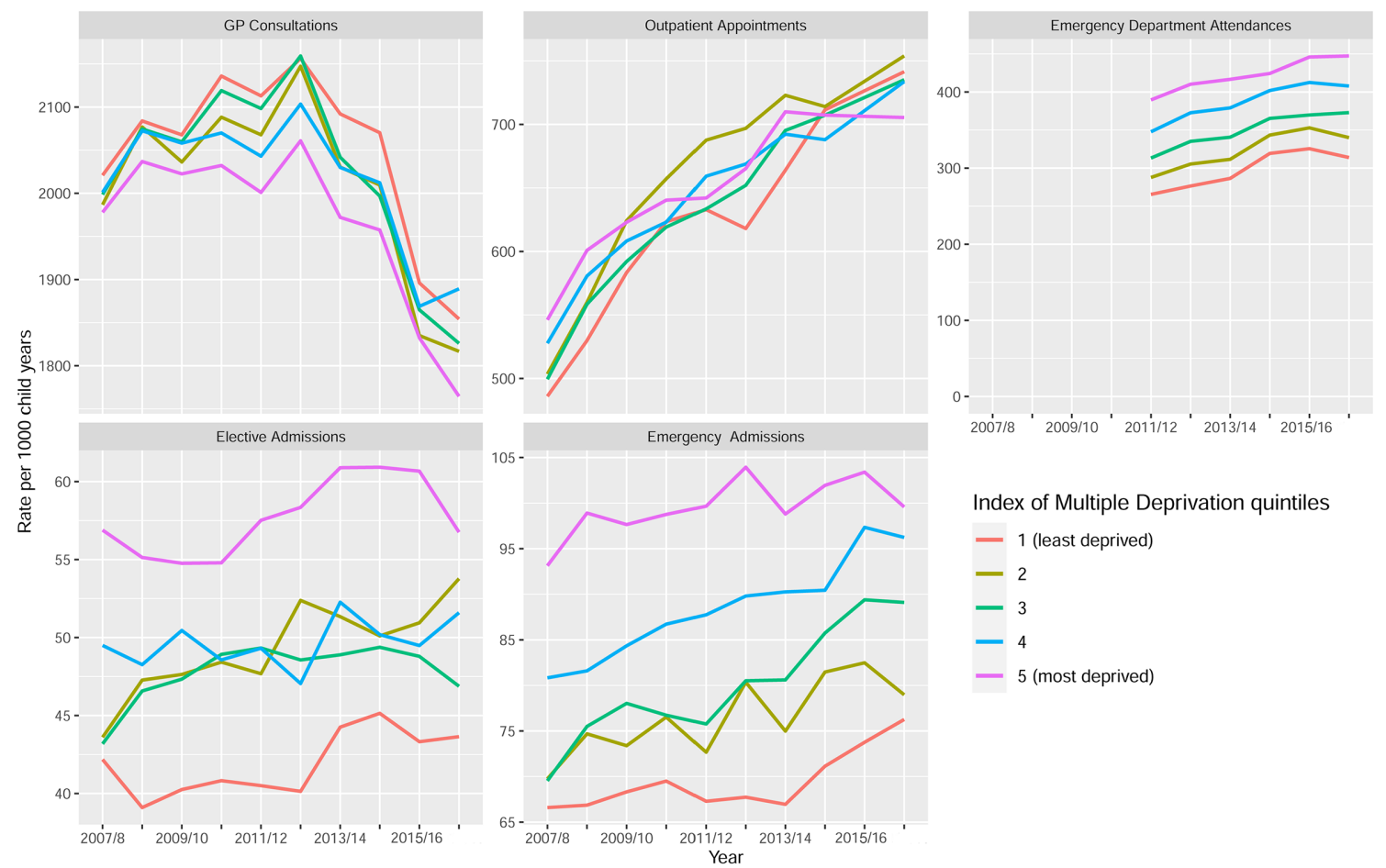

Index of Multiple Deprivation quintiles

1 (least deprived)

$-2$

$-3$

$-4$

- 5 (most deprived)

Emergency Department Attendance data prior to 2011 was not comparable

Health Utilization Rates for Children under 15 years old by Ethnic Group and Healthcare Setting, England 2007-2017
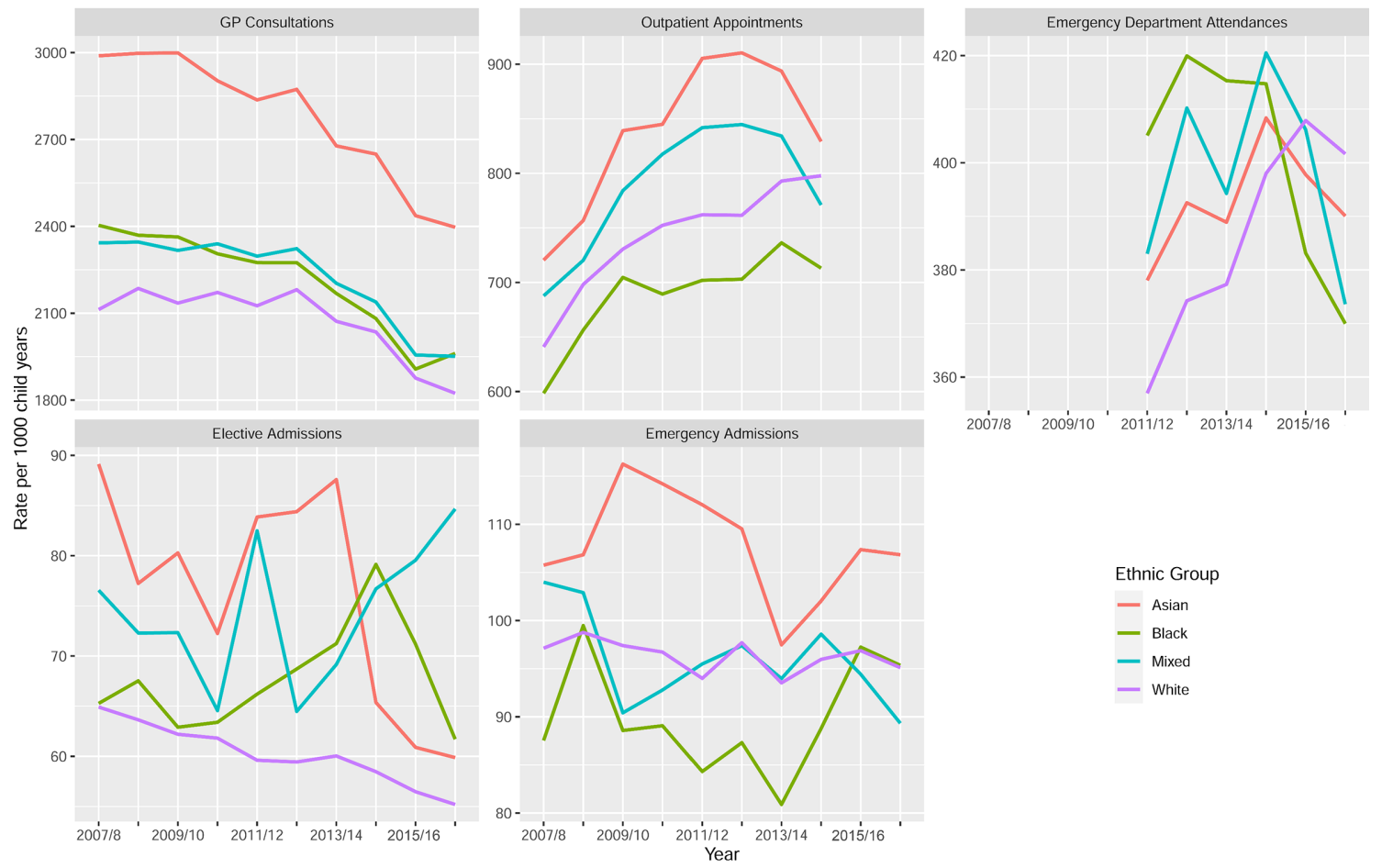

Emergency Department Attendance data prior to 2011 was not comparable

Figure 1 Social and ethnic differences in children's healthcare use graphs. GP, general practitioner.

\section{Ethnicity}

In 2016/2017, compared with children from white ethnic groups, black children accounted for more GP consultations (1961 vs 1824 per 1000) and elective admissions (62 vs 55 per 1000). Emergency admission rates were the same in both groups
(95 per 1000), but black children had fewer outpatient attendances (732 vs 809 per 1000) and ED visits (370 vs 402 per 1000). Compared with children from white ethnic groups, the ratio of ED activity in those from black ethnic groups reversed from $13.5 \%(10.6,16.3)$ higher to $8 \%(4.0,11.9)$ lower between 
Table 2 Ratio of mean utilisation rates by healthcare setting and social and ethnic group

\begin{tabular}{|c|c|c|c|}
\hline \multicolumn{2}{|l|}{ Outcome of interest } & Baseline & $2016 / 17$ \\
\hline \multicolumn{4}{|c|}{ Ratio of mean utilisation rates in children belonging to the most vs least deprived groups } \\
\hline \multirow{2}{*}{\multicolumn{2}{|c|}{ GP consultations }} & Ratio (Lower and Upper 95\% Cl) & Ratio (Lower and Upper 95\% Cl) \\
\hline & & $97.9 \%$ (97.4 to 98.3$)$ & $95.2 \%$ (94.4 to 96.0$)$ \\
\hline \multicolumn{2}{|l|}{ Outpatient attendances } & $112.4 \%(110.9$ to 113.8$)$ & $95.1 \%$ (93.6 to 96.7$)$ \\
\hline \multicolumn{2}{|l|}{ ED visits } & $146.8 \%(145.1$ to 149.3$)$ & $142.5 \%(138.7$ to 146.2$)$ \\
\hline \multicolumn{2}{|l|}{ Emergency admissions } & $139.9 \%(133.6$ to 144.2$)$ & $130.6 \%(123.1$ to 140.7$)$ \\
\hline \multicolumn{2}{|l|}{ Elective admissions } & $134.9 \%(127.7$ to 144.4$)$ & $130.1 \%(119.7$ to 140.2$)$ \\
\hline \multicolumn{4}{|c|}{ Ratio of mean utilisation rates in children from black, Asian and mixed ethnic groups vs children from white ethnic groups } \\
\hline \multirow[t]{3}{*}{ GP consultations } & Black & $113.8 \%$ (112.8 to 114.7$)$ & $107.5 \%$ (106.2 to 108.8$)$ \\
\hline & Asian & $141.5 \%$ (140.5 to 142.4$)$ & $131.4 \%$ (130.1 to 132.8$)$ \\
\hline & Mixed & $110.9 \%$ (109.7 to 112.1$)$ & $107.0 \%(105.5$ to 108.5$)$ \\
\hline \multirow[t]{3}{*}{ Outpatient attendances } & Black & $93.3 \%$ (90.9 to 95.7$)$ & $90.5 \%$ (87.6 to 93.3 ) \\
\hline & Asian & $112.3 \%$ (110.2 to 114.4$)$ & $98.9 \%(96.3$ to 101.4$)$ \\
\hline & Mixed & 107.3 (104.4 to 110.2$)$ & $91.1 \%$ (88.2 to 94.0$)$ \\
\hline \multirow[t]{3}{*}{ ED visits } & Black & $113.5 \%$ (110.6 to 116.3$)$ & $92.0 \%$ (88.1 to 96.0 ) \\
\hline & Asian & $105.9 \%$ (103.6 to 108.2$)$ & $97.0 \%$ (93.6 to 100.4$)$ \\
\hline & Mixed & $107.3 \%(104.0$ to 110.6$)$ & $93.0 \%$ (88.8 to 97.3 ) \\
\hline \multirow[t]{3}{*}{ Emergency admissions } & Black & $90.7 \%$ (82.5 to 99.0$)$ & $100.0 \%$ (90.0 to 110.1$)$ \\
\hline & Asian & $109.2 \%(102.0$ to 116.0$)$ & $112.4 \%(102.3$ to 121.1$)$ \\
\hline & Mixed & $107.2 \%(98.0$ to 117.0$)$ & $93.7 \%$ (82.8 to 104.7$)$ \\
\hline \multirow[t]{3}{*}{ Elective admissions } & Black & $100.0 \%$ (87.8 to 112.3$)$ & $112.7 \%$ (100.3 to 125.4$)$ \\
\hline & Asian & $136.9 \%(126.3$ to 147.7$)$ & $109.1 \%$ (98.4 to 120.0 ( \\
\hline & Mixed & $118.5 \%$ (104.2 to 132.9$)$ & $154.6 \%$ (141.3 to 168.2$)$ \\
\hline
\end{tabular}

Baseline year for GP consultations, outpatient attendances, emergency admission and elective admissions—2007/2008.

Baseline year for ED visits—2011/2012.

$E D$, emergency department; GP, general practitioner.

2011/2012 and 2016/2017. In 2007/2008, outpatient activity was $6.7 \%$ lower in children from black ethnic groups than in children from white ethnic groups. We observed a similar difference of $9.5 \%(6.7,12.4)$ in $2016 / 2017$.

In 2007/2008, GP consultation rates were 2989 per 1000 in children from Asian ethnic groups and 2113 per 1000 in children from white ethnic groups. Consultation rates fell in both groups across the study period, but remained over 30\% higher in children from Asian groups than in white CYP (2397 vs 1824 per 1000) in 2016/2017. At baseline, children from Asian groups had higher ED, outpatient and in-patient activity than white children. These differences were not seen in 2016/2017.

\section{DISCUSSION}

In this large population-based retrospective cohort study, we report marked social and ethnic group differences in children's healthcare use in England. During a decade in which child health inequalities widened, use of scheduled and unscheduled care diverged between children living in affluent and deprived postcodes. While outpatient attendance rates were relatively low among children from black ethnic groups across the study period, GP consultation rates remained significantly higher in black and Asian children than among their white peers. By 2016/2017, we found broadly similar overall rates of ED and in-patient activity. Our data suggest that children from black and Asian groups have greater access to primary care services than white children living in England. However, the high rates of adverse child health outcomes in racially minoritised groups indicate that further work is needed to determine whether health service utilisation is proportionate to need.

As described elsewhere, ${ }^{13}$ GP consultation rates for all groups significantly outnumbered other forms of healthcare utilisation across the study period. Our study suggests that children living in more affluent areas of England receive more scheduled care in GP practices and specialist clinics, while those from deprived neighbourhoods are more likely to receive unscheduled care. ED visits and hospital admissions are sometimes necessary and appropriate. However, they may result from restricted access to primary care or a failure of successful management in other settings. Previous work has shown that children with greater access to GP appointments in and out-of-hours have significantly lower ED visit rates. ${ }^{18}$ The geographical accessibility of English GP practices is similar in affluent and deprived areas. ${ }^{19}$ This suggests factors other than proximity also contribute to relatively low use of GP services among CYP from deprived neighbourhoods. GPs in the most deprived areas of England have 15\% larger case-loads than GPs working in the most affluent areas. ${ }^{20}$ Low parental health literacy is associated with suboptimal preventive care behaviours and inappropriate ED attendances, ${ }^{21} 22$ and children living in more deprived areas of England are less likely to engage with preventive care and more likely to require unplanned hospital admission. ${ }^{23}$ Few studies have linked parental socioeconomic status, health literacy and child health outcomes, but low health literacy clusters in deprived groups. ${ }^{24}$ Work with deprived communities has also highlighted practical barriers to accessing scheduled care. These include difficulties in obtaining appointments in-hours, securing time off work and unacceptable travel costs. ${ }^{25}$ With GPs acting as gatekeepers to specialist services, restricted access to primary care may also hinder access to specialist advice. It is concerning that recent studies have highlighted reduced access to tertiary services among children living in deprived areas of England. ${ }^{2627}$

Proportionate universalism is required to ensure equitable health outcomes for children belonging to different ethnic 
groups. Individuals and populations with relatively high health needs require increased access to health services. In 2007/2008, this greater need was reflected in higher GP activity for all ethnic groups and higher outpatient activity in children from Asian and mixed ethnic groups. Previous studies have highlighted similar, high levels of primary care activity among children and adults from Asian ethnic groups living in England. ${ }^{82}$ While GP activity in all ethnic groups reverted towards levels seen in white groups, it remained relatively high among Asian children. However, it is concerning to see relatively low outpatient activity in children from black ethnic groups. As in adults, much remains to be done to ensure the needs of children belonging to racially minoritised groups are met. ${ }^{29}$

\section{Strengths and limitations}

The strengths of this study include its large size, national coverage and representative study population, which reduce the likelihood that our results were due to chance. To our knowledge, this is the largest nationally representative population-based study to assess social and ethnic group trends in children's healthcare use in England across all settings. However, as a sample of the population, our data show wider year-on-year variation for inpatient admissions than previous analysis of national inpatient data. ${ }^{30}$ Our analysis did not include data from NHS walk-in centres. NHS 111 services or Child and Adolescent Mental Health services. The composition and volume of missing data in our ethnicity analysis changed over the study period (online supplemental appendix 1). While our $2016 / 2017$ population profile broadly matched 2011 UK census data, ${ }^{31}$ trends within each ethnic group should be interpreted with caution due to relatively low representation of racially minoritised groups in our $2007 / 2008$ population. Nonetheless, differing trends in healthcare use across different settings suggest that changes in ethnicity coding completeness alone cannot explain our findings. We used five composite non-homogenous ethnic groups in our analysis, as recommended by the UK ONS to increase consistency and comparability of data. However, we recognise that this is a crude approach which overlooks the complex, self-defined nature of ethnicity and may mask significant within-group differences in socioeconomic and health status, such as those between children from Bangladeshi and Chinese ethnic groups living in the UK. As in other studies using CPRD data, ${ }^{32}$ we observed attrition in study population sizes as GP practices transitioned to new electronic patient records. Nonetheless, previous studies have shown very little evidence of systematic bias in the composition of the CPRD population over time. ${ }^{33}$ Around 30\% of black British children live in economically deprived circumstances, compared with $17 \%$ of white British children. ${ }^{34}$ As we have not adjusted for deprivation, our findings may underestimate or overestimate the association between ethnicity and children's healthcare use. Finally, IMD provides information on deprivation at neighbourhood level, which may mask household-level variation in parental socioeconomic status in diverse postcodes.

\section{Implications}

This study highlights marked social and ethnic inequalities in children's healthcare use in England. Our findings raise concern that the most vulnerable children may be less likely to receive the prevention, health promotion and specialist support which may be most protective against future health problems. Previous work has identified differences in the ability of different health systems to meet children's health needs in an equitable way. For example, one study found that healthcare activity in the Netherlands was well-matched to need, whereas children living in low-income households in the USA experienced a double burden of worse health and less contact with services. ${ }^{35}$ It is concerning that patterns of children's healthcare use in England appear closer to those seen in the USA, despite the NHS offering healthcare free at the point of delivery. While context and effective interventions will vary across areas and communities, a combination of the approaches outlined in box 2 could help to deliver more equitable services in England.

\section{CONCLUSION}

This study identifies divergent patterns of healthcare use along a social gradient among children aged 0-14 years in England. Children living in more deprived areas have higher ED and in-patient activity, while affluent groups have higher rates of GP and outpatient consultation. Across the study period, outpatient

Box 2 Policy and practice interventions to reduce social and ethnic inequalities in children's healthcare

\section{Education and training for patients, families and professionals}

There is evidence that some health professionals lack confidence and experience in supporting patients from minoritised groups. ${ }^{36}$ Training in cultural competence has been well received by child health professionals and could help to address this skills gap. ${ }^{37} 38$ A universal teaching programme which provides school-age children and new parents with information on their rights and responsibilities, available services and entitlements could also improve health literacy and support self-care.

Integrated community child health and health literacy Community health interventions have been found to reduce inequity in health outcomes in low-income and middle-income settings, ${ }^{39}$ Evidence-based decision support tools and in-person navigation interventions can encourage appropriate child healthcare utilisation. ${ }^{40} \mathrm{GP}$ consultations significantly outnumber other forms of clinical consultation between children and healthcare professionals. Integration of care around GP services therefore constitutes a logical means of addressing inequalities in healthcare utilisation. Integrated services have the potential to mitigate and prevent health inequalities, through timely recognition and management of new health problems, coordination and continuity of care and health promotion interventions. ${ }^{41}$ Future research on Integrated Care Systems within the English NHS must assess their impact on health inequalities in children and young people.

Community engagement in health service development, staffing and research

Sustainable engagement of disadvantaged and racially minoritised communities in health service development and improvement is essential if we are to address inequalities in the long term. ${ }^{42}$ Engaging community groups that are representative of diverse local populations helps to create user-friendly services and address the underlying reasons for poor health. ${ }^{43}$ Similarly, involving members of racially minoritised and disadvantaged social groups in a participatory research process is likely to help us better understand the reasons for specific differences in healthcare use between ethnic groups. ${ }^{44}$ Efforts to increase representation of health professionals from racially minoritised groups may increase the availability of culturally congruent care, ${ }^{45}$ which has been linked to striking improvements in infant mortality among children from black groups in the USA. ${ }^{46}$ 
activity was lower in children from black ethnic groups than in those from White and Asian groups. GP consultations remained higher in children from black and Asian groups than in white children, and by 2016/2017, outpatient, ED and in-patient activity were similar in children from white and Asian groups. While these data indicate that children from different ethnic groups have relatively equal access to health services in England, the disproportionately high rates of adverse child health outcomes in racially minoritised groups suggest an urgent need for further work to determine whether health service utilisation is proportionate to need. Considered alongside rising child poverty and widening child health inequalities, our findings suggest significant levels of unmet need among CYP living in more deprived areas of England.

\section{Twitter Sonia Saxena @SoniaKSaxena}

Acknowledgements We would like to thank Elizabeth Cecil and Geva Greenfield for their support and feedback.

Contributors $\mathrm{DH}$, SS and MB conceived and designed this study. JR prepared the data and conducted the CPRD-HES analysis. Data were interpreted by CHC, DH, MB and SS. CHC, FKN and BNM performed a literature review and CHC wrote the first draft. This was critically revised for intellectual content by MB, SS and DH. All authors have approved the final version of the manuscript.

Funding This article presents independent research commissioned by the National Institute for Health Research (NIHR) under the Applied Health Research (ARC) programme for North West London. SS is also supported by the NIHR School for Public Health Research Programme. The Dr Foster Unit at Imperial College London is affiliated with the NIHR Imperial Patient Safety Translational Research Centre. This is a collaboration between Imperial College Healthcare NHS Trust and Imperial College London. The Child Health Unit and Dr Foster Unit are grateful for support from the NIHR Biomedical Research Council funding scheme.

Disclaimer We are unable to directly share results with participants or their caregivers as this study used deidentified patient data. However, the results of this study will be disseminated to the public through press releases, social media postings and media commentary.

Competing interests DH is Deputy Chief Scientific Advisor to the Department for Education

\section{Patient consent for publication Not required.}

Ethics approval The Independent Scientific Advisory Committee granted ethical and scientific approval for the use of CPRD in our study. Protocol number: 18_139.

Provenance and peer review Not commissioned; externally peer reviewed.

Data availability statement No data are available. Due to data sharing agreements, data are unavailable for sharing publicly. Data may be obtained from a third party (the Clinical Practice Research Datalink) and are not publicly available.

Supplemental material This content has been supplied by the author(s). It has not been vetted by BMJ Publishing Group Limited (BMJ) and may not have been peer-reviewed. Any opinions or recommendations discussed are solely those of the author(s) and are not endorsed by BMJ. BMJ disclaims all liability and responsibility arising from any reliance placed on the content. Where the content includes any translated material, BMJ does not warrant the accuracy and reliability of the translations (including but not limited to local regulations, clinical guidelines, terminology, drug names and drug dosages), and is not responsible for any error and/or omissions arising from translation and adaptation or otherwise.

Open access This is an open access article distributed in accordance with the Creative Commons Attribution Non Commercial (CC BY-NC 4.0) license, which permits others to distribute, remix, adapt, build upon this work non-commercially, and license their derivative works on different terms, provided the original work is properly cited, appropriate credit is given, any changes made indicated, and the use is non-commercial. See: http://creativecommons.org/licenses/by-nc/4.0/.

\section{ORCID iDs}

Charles Hamish Coughlan http://orcid.org/0000-0003-3907-3859

Behrouz Nezafat Maldonado http://orcid.org/0000-0002-7488-5564

Sonia Saxena http://orcid.org/0000-0003-3787-2083

\section{REFERENCES}

1 Royal College of Paediatrics and Child Health. State of child health 2020: England. Available: www.stateofchildhealth.rcpch.ac.uk/evidence/nations/england [Accessed 21 May 2020].
2 Public Health England. Public health outcomes framework health equity report: focus on ethnicity. Available: https://assets.publishing.service.gov.uk/government/uploads/ system/uploads/attachment_data/file/733093/PHOF_Health_Equity_Report.pdf [Accessed 23 May 2020].

3 Kumar S, Tadakamadla J, Kroon J, et al. Impact of parent-related factors on dental caries in the permanent dentition of 6-12-year-old children: a systematic review. J Dent 2016;46:1-11.

4 Asthma UK. On the edge: how inequality affects people with asthma. Available: https://www.asthma.org.uk/dd78d558/globalassets/get-involved/external-affairscampaigns/publications/health-inequality/auk-health-inequalities-final.pdf [Accessed 10 Jun 2020].

5 Reiss F. Socioeconomic inequalities and mental health problems in children and adolescents: a systematic review. Soc Sci Med 2013:90:24-31.

6 Moreno-Serra R, Smith PC. Does progress towards universal health coverage improve population health? Lancet 2012:380:917-23.

7 Schneider EC, Sarnak DO, Squires D. Mirror, mirror 2017: international comparison reflects flaws and opportunities for better us. health care. The Commonwealth Fund, 2017.

8 Saxena S, Eliahoo J, Majeed A. Socioeconomic and ethnic group differences in self reported health status and use of health services by children and young people in England: cross sectional study. BMJ 2002;325:520

9 Hood A, Waters T. Living Standards, poverty and inequality in the UK: 2016-17 to 2021-22. Great Britain Institute for Fiscal Studies, 2017.

10 Rajmil L, Hjern A, Spencer N, et al. Austerity policy and child health in European countries: a systematic literature review. BMC Public Health 2020;20:564.

11 Taylor-Robinson D, Lai ETC, Wickham S, et al. Assessing the impact of rising child poverty on the unprecedented rise in infant mortality in England, 2000-2017: time trend analysis. BMJ Open 2019:9:e029424.

12 Marshall M. A precious jewel--the role of general practice in the English NHS. N Eng/ J Med 2015:372:893-7.

13 Ruzangi J, Blair M, Cecil E, et al. Trends in healthcare use in children aged less than 15 years: a population-based cohort study in England from 2007 to 2017. BMJ Open 2020:10:e033761.

14 Herrett E, Gallagher AM, Bhaskaran K, et al. Data resource profile: clinical practice research Datalink (CPRD). Int J Epidemiol 2015:44:827-36.

15 UK Government. List of ethnic groups. Available: https://www.ethnicity-facts-figures. service.gov.uk/ethnic-groups [Accessed 10 Jun 2020].

16 Ministry of Housing, Communities and Local Government. The English indices of multiple deprivation 2019 (IoD2019). Available: https://assets.publishing.service.gov. uk/government/uploads/system/uploads/attachment_data/file/835115/loD2019_ Statistical_Release.pdf [Accessed 10 Jun 2020].

17 Fieller EC. The biological standardization of insulin. Suppl to I R Statist Soc 1940;7:1-64.

18 Cecil E, Bottle A, Cowling TE, et al. Primary care access, emergency department visits, and unplanned short hospitalizations in the UK. Pediatrics 2016;137:e20151492.

19 Todd A, Copeland A, Husband A, et al. Access all areas? an area-level analysis of accessibility to general practice and community pharmacy services in England by urbanity and social deprivation. BMJ Open 2015:5:e007328

20 Gershlick B, Fisher R. A worrying cycle of pressure for GPs in deprived areas. The health Foundation. Available: https://www.health.org.uk/news-and-comment/ blogs/a-worrying-cycle-of-pressure-for-gps-in-deprived-areas [Accessed $18 \mathrm{Sep}$ 2020].

21 Sanders LM, Federico S, Klass P, et al. Literacy and child health: a systematic review. Arch Pediatr Adolesc Med 2009;163:131-40.

22 Butun A, Linden M, Lynn F, et al. Exploring parents' reasons for attending the emergency department for children with minor illnesses: a mixed methods systematic review. Emerg Med J 2019:36:39-46.

23 Cecil E, Bottle A, Ma R, et al. Impact of preventive primary care on children's unplanned hospital admissions: a population-based birth cohort study of UK children 2000-2013. BMC Med 2018;16:151.

24 Public Health England and UCL Institute for Health Equity. Local action on health inequalities: improving health literacy to reduce health inequalities. Available: www. gov.uk/government/publications/local-action-on-health-inequalities-improving-healthliteracy [Accessed 15 Jun 2020].

$25 \mathrm{O}^{\prime}$ Cathain A, Connell J, Long J, et al. 'Clinically unnecessary' use of emergency and urgent care: a realist review of patients' decision making. Health Expect 2020;23:19-40.

26 Jay MA, Howard RF. Inequalities in access to a tertiary children's chronic pain service: a cross-sectional study. Arch Dis Child 2016;101:657-61.

27 Neale FK, Armstrong EJ, Cohen JM, et al. How fair is our service? evaluating access to specialist paediatric care. Arch Dis Child 2019;104:1105-7.

28 Nazroo JY, Falaschetti E, Pierce M, et al. Ethnic inequalities in access to and outcomes of healthcare: analysis of the health survey for England. J Epi Comm Health 2009;63:1022-7.

29 Salway S, Holman D, Lee C. Transforming the health system for the UK's multi-ethnic population. BMJ 2020;11:368.

30 Kossarova L, Cheung R, Hargreaves D. Admissions of inequality: emergency Hospital use for children and young people. Nuffield trust 2017. Available: https://www. 


\section{Original research}

nuffieldtrust.org.uk/files/2017-12/nt-admissions-of-inequality-web.pdf [Accessed 13 Sep 2020].

31 Mathur R, Bhaskaran K, Chaturvedi N, et al. Completeness and usability of ethnicity data in UK-based primary care and hospital databases. J Public Health 2014;36:684-92.

32 Sun X, Gulliford MC. Reducing antibiotic prescribing in primary care in England from 2014 to 2017: population-based cohort study. BMJ Open 2019;9:e023989.

33 Wolf A, Dedman D, Campbell J, et al. Data resource profile: clinical practice research Datalink (CPRD) aurum. Int J Epidemiol 2019;48:1740-1740g.

34 UK Office for National Statistics. Child poverty and educational outcomes by ethnicity. Available: https://www.ons.gov.uk/economy/nationalaccounts/uksectoraccounts/ compendium/economicreview/february2020/childpovertyandeducationoutcomesbyet hnicity [Accessed 22 Jun 2020].

35 Hargreaves DS, Struijs JN, Schuster MA. Us children and adolescents had fewer annual doctor and dentist contacts than their Dutch counterparts, 2010-12. Health Aff 2015;34:2113-20.

36 Kai J, Beavan J, Faull C, et al. Professional uncertainty and disempowerment responding to ethnic diversity in health care: a qualitative study. PLoS Med 2007:4:e323.

37 Webb E, Sergison M. Evaluation of cultural competence and antiracism training in child health services. Arch Dis Child 2003;88:291-4.

38 Sorensen J, Norredam M, Dogra N, et al. Enhancing cultural competence in medical education. Int J Med Educ 2017;8:28-30.
39 Yuan B, Målqvist $\mathrm{M}$, Trygg $\mathrm{N}$, et al. What interventions are effective on reducing inequalities in maternal and child health in low- and middle-income settings? A systematic review. BMC Public Health 2014;14:634.

40 Pantell MS, Hessler $D$, Long $D$, et al. Effects of in-person navigation to address family social needs on child health care utilization: a randomized clinical trial. JAMA Netw Open 2020:3:e206445.

41 Watt G. What can the NHS do to prevent and reduce health inequalities? Br I Gen Pract 2013:63:494-5.

42 NHS Confederation BME Leadership Forum. Engaging with BME communities: insights for impact. Available: https://www.nhsconfed.org/ /media/Confederation/ Files/Publications/Documents/Engaging-BME-communities-insights-for-impact.pdf [Accessed 7 Mar 2021].

43 Blomfield M, Cayton H. Community engagement report for the health Foundation. health Foundation, 2010. Available: https://www.health.org.uk/publications/ community-engagement [Accessed 7 Mar 2021].

44 Dawson S, Campbell SM, Giles SJ, et al. Black and minority ethnic group involvement in health and social care research: a systematic review. Health Expect 2018;21:3-22.

45 Betancourt JR, Green AR, Carrillo JE, et al. Defining cultural competence: a practical framework for addressing racial/ethnic disparities in health and health care. Public Health Rep 2003;118:293-302.

46 Greenwood BN, Hardeman RR, Huang L, et al. Physician-Patient racial concordance and disparities in birthing mortality for newborns. Proc Natl Acad Sci U SA 2020;117:21194-200. 